\title{
Contribution of Particles Size Ranges to Sand Friction
}

\author{
Esma Mostefa Kara \\ Djillali Liabes University \\ Dept. Civil Engineering, Fac.Technology \\ Labo. Civil Engineering \& Environment \\ (LGCE) \\ Sidi Bel Abbes, Algeria \\ mkesma@univ-sba.dz
}

\author{
Mourad Meghachou \\ Djillali Liabes University \\ Dept. Civil Engineering, Fac.Technology \\ Labo. Civil Engineering \& Environment \\ (LGCE) \\ Sidi Bel Abbes, Algeria \\ mourad_meghachou@univ-sba.dz
}

\author{
Nabil Aboubekr \\ Tlemcen University \\ Dept. Civil Engineering, Fac.Technology \\ Labo. Water and Structures in their \\ Environment (EOLE) \\ Tlemcen, Algeria \\ aboubekrnabil@yahoo.fr
}

\begin{abstract}
This work studies the correlation between certain physical properties of granular material such as the friction angle and the grain size distribution. In the laboratory, the determination of friction angle requires hard and expensive testing. Prediction of this parameter from the grading curve proves to be very interesting. Direct shear tests were performed on actual marine sand of Tergha (Algeria) and on seventeen different samples arranged from the same sand with various particle size ranges. Results showed that the friction angle of sand is a result of contribution of various constituent granular classes.
\end{abstract}

Keywords-component; sand; peak friction angle; particle size range; shear test; grading curve.

\section{INTRODUCTION}

The shear strength of sands was first introduced by Coulomb. He simply assumed that frictional resistance increases with normal pressure. In fact, there are three components contributing to the strength of sand [1-4]. According to [4], these components are:

- $\quad$ strength mobilized by frictional resistance

- strength developed by energy required to cause expansion or dilation of materials

- $\quad$ strength developed by energy required to rearrange and reorient materials

The first component is usually described as sliding friction, the second as interlocking friction, and the third as rolling friction.

Yong explained that sliding friction is included by microscopic interlocking arising from surface roughness; interlocking friction is caused by the physical resistance to relative particle translation affected by adjacent particles. The third component, rolling friction, might be ignored [5].

The nature of contacts between particles of soil directly influences its frictional character. Dense sand, loaded in shearing, presents at early stage tangle grains which mobilize more friction and therefore shear strength. It is accepted now that the critical state reached for the sand, when subjected to large deformations whatever its density, gives the material a quasi-constant friction angle [6, 7].
However, the maximum friction angle characterizing the beginning of rupture and before the establishment of the critical state can be correlated with many parameters, among others, grain size distribution [8-11]. According to studies [12-15] made on various sands with constant density, friction angle increases with the reduction of particle size with an insignificant variation. Other researches, aiming at the variation of internal friction angle according to the gradation, have shown that the friction angle increases with the increase of the Uniformity Coefficient (UC) for sands consisting of feldspar and calcite $[9,10]$. On the other hand, for sands consisting mainly of quartz, the studies did not show any bond between the two [15-20]. And thus, with constant void ratio, the size of the particles does not seem to have significant influence on the friction angle. Consequently, a fine sand and a coarse sand presenting the same mineralogical composition and the same void ratio will probably have the same value of friction angle. However, by carrying out direct shear tests on samples of sand with the same void ratio but with different size, one finds considerable variations of friction angle.

In summary, the effect of particle size on friction angles of cohesionless materials is not clear through the literature. The study described in this paper answers the following question: what is the relationship between the peak friction angle and the grain size distribution of sand?

\section{EXPERIMENTAL PROGRAM}

The experimental study follows three stages:

- Separation of the various particles size ranges constituting the studied sand

- Reconstitution of ten samples, with different percentages from the seven particles size ranges;

- Realization of direct shear tests on Tergha sand and seventeen other samples derived from it.

\section{A. Description of Tergha sand}

The distribution of particle sizes is obtained by dry sieving sand of known weight through a stack of sieves of progressively finer mesh size with a respect to the norm NF P94-056. According to classification LCPC, our sand is gapgraded (Figure 1). Figure 2 shows a photo of Tergha sand and a microscopic view is shown in Figure 3. 
The granular properties of Tergha sand are:

- Diameter of the soil particles for which $10 \%$ of the particles are finer $\left(d_{10}\right)$ is $0,20 \mathrm{~mm}$

- Diameter of the soil particles for which $30 \%$ of the particles are finer $\left(d_{30}\right)$ is $0,24 \mathrm{~mm}$

- Diameter of the soil particles for which $60 \%$ of the particles are finer $\left(d_{60}\right)$ is $0,31 \mathrm{~mm}$

- Uniformity coefficient (UC) is: 1,53

- Coefficient of curvature (CC) is: 0,92

- $\quad$ Maximum void ratio (loosest condition) $\left(\mathrm{e}_{\max }\right): 0,8$

- Minimum void ratio (densest condition) ( $\left.\mathrm{e}_{\mathrm{min}}\right): 0,52$

The density of the solid particles of Tergha sand is given according to NF P94-054: $\gamma_{s}=2.65 \mathrm{~g} / \mathrm{cm}^{3}$.

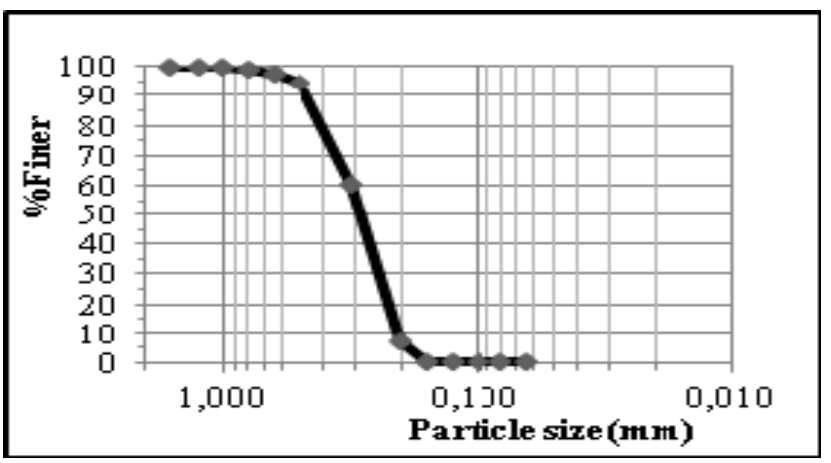

Fig. 1. Grading curve of Tergha sand

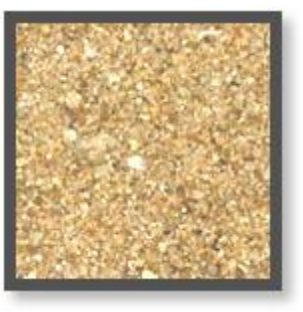

Fig. 2. Photography of Tergha sand.

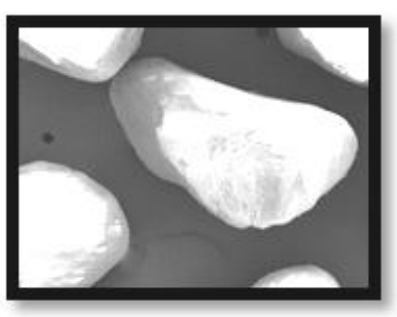

Fig. 3. Microscopic view of Tergha sand $($ zoom $\times 220)$.

\section{B. Particles size ranges}

Seven particles size ranges are studied after separation: ([1, $0,8],[0.8,0.63],[0.63,0.5],[0.5,0.315],[0.315,0.2],[0.2$, $0.160]$ and $[0.160,0.125])$ [mm]. Each one of these classes is represented in the study by the smallest diameter of the class $\left(d_{i}\right)$. Figure 4 represents photo of the various ranges. Figure 5 represents a microscopic view $($ zoom $\times 220)$ of two particle size ranges and Table I gathers the various grain size properties of the various reconstituted samples. It should be noted that the tenth sample in Table I (S10) is composed of $50 \%$ of the smallest class and $50 \%$ of the biggest class.

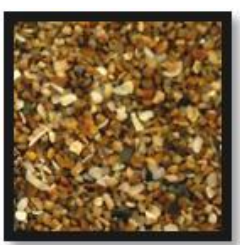

$[0.8,0.63] \mathrm{mm}$

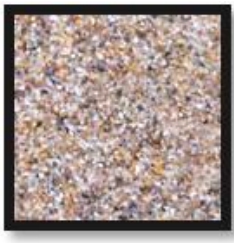

$[0.315,0.2] \mathrm{mm}$

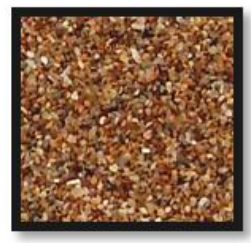

$[0.63,0.5] \mathrm{mm}$

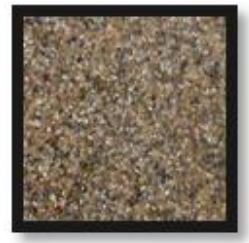

[0.2, 0.160] mm

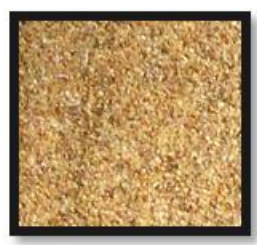

$[0.5,0.315] \mathrm{mm}$

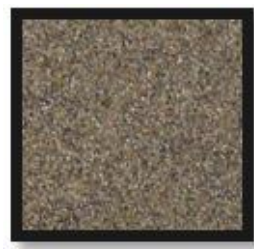

$[0.160,0.125] \mathrm{mm}$
Fig. 4. Photography of particles size ranges.

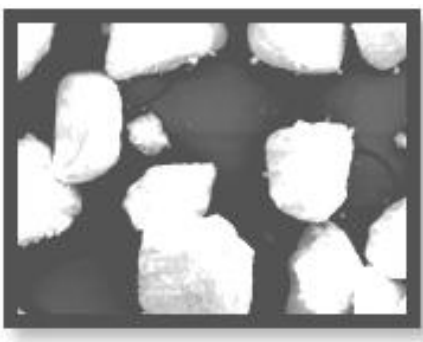

$[0.160,0.125] \mathrm{mm}$

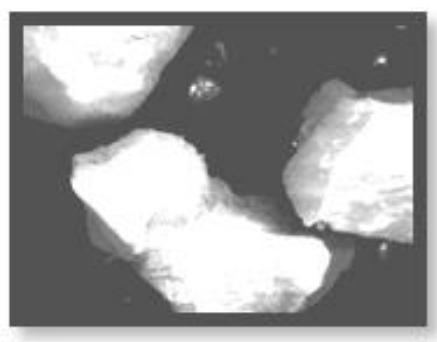

[0. 5,0.315] mm
Fig. 5. Microscopic view of two particles size ranges $(\mathrm{zoom} \times 220)$.

TABLE I. GRANULAR PROPERTIES OF SAMPLES.

\begin{tabular}{|c|c|c|c|c|c|c|c|}
\hline Sample & $\begin{array}{c}\boldsymbol{d}_{\mathbf{1 0}} \\
\mathbf{m m}\end{array}$ & $\begin{array}{c}\boldsymbol{d}_{\mathbf{3 0}} \\
\mathbf{m m}\end{array}$ & $\begin{array}{c}\mathbf{d}_{\mathbf{6 0}} \\
\mathbf{m m}\end{array}$ & $\mathbf{U C}$ & $\mathbf{C C}$ & $\mathbf{e}_{\mathbf{m a x}}$ & $\mathbf{e}_{\mathbf{m i n}}$ \\
\hline S1 & 0,16 & 0,22 & 0,41 & 2,50 & 0,75 & 0,709 & 0,45 \\
\hline S2 & 0,21 & 0,24 & 0,30 & 1,42 & 0,93 & 0,811 & 0,535 \\
\hline S3 & 0,18 & 0,28 & 0,38 & 2,13 & 1,16 & 0,737 & 0,474 \\
\hline S4 & 0,15 & 0,34 & 0,54 & 3,66 & 1,43 & 0,64 & 0,393 \\
\hline S5 & 0,16 & 0,23 & 0,60 & 3,64 & 0,53 & 0,641 & 0,394 \\
\hline S6 & 0,14 & 0,17 & 0,31 & 2,28 & 0,63 & 0,725 & 0,464 \\
\hline S7 & 0,31 & 0,63 & 0,86 & 2,74 & 1,46 & 0,693 & 0,437 \\
\hline S8 & 0,17 & 0,2 & 0,31 & 1,88 & 0,76 & 0,76 & 0,493 \\
\hline S9 & 0,16 & 0,23 & 0,54 & 3,37 & 0,63 & 0,655 & 0,405 \\
\hline S10 & - & - & - & - & - & - & - \\
\hline
\end{tabular}

\section{Reconstituted samples}

Ten samples are reconstituted from the seven particles size ranges with a random choice of percentage. Figure 6 represent the composition of the different samples.

\section{Tests}

Several direct shear tests are applied to the eighteen samples referred to above (one of actual Tergha sand, seven samples with different particle size ranges and ten reconstituted samples with random percentages of particle size ranges). The tests are carried out in a dry and dense state. The line of rupture is obtained following the application of five normal stresses $(100,200,300,400$ and $600 \mathrm{kPa})$ to obtain more precision for 
the statistical study. The dry gravities of the various sheared samples are listed in Table II. Figure 7 shows that the state of density is almost identical for all studied samples.

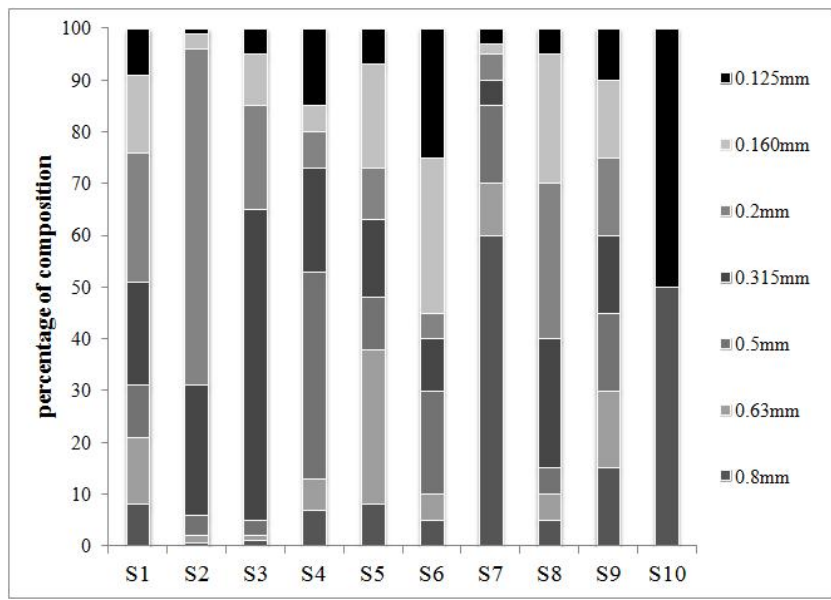

Fig. 6. Composition of the various reconstituted samples

TABLE II. DRY GRAVITY OF SAMPLES

\begin{tabular}{|c|c|c|c|c|c|}
\hline $\begin{array}{c}\sigma(\mathbf{k P a}) \\
\text { Sample }\end{array}$ & $\mathbf{1 0 0}$ & $\mathbf{2 0 0}$ & $\mathbf{3 0 0}$ & $\mathbf{4 0 0}$ & $\mathbf{6 0 0}$ \\
\hline Tergha Sand & 1,67 & 1,72 & 1,65 & 1,69 & 1,71 \\
\hline$[1,0.8]$ & 1,52 & 1,49 & 1,51 & 1,49 & 1,44 \\
\hline$[0.8,0.63]$ & 1,65 & 1,61 & 1,61 & 1,63 & 1,61 \\
\hline$[0.63,0.5]$ & 1,69 & 1,65 & 1,63 & 1,65 & 1,65 \\
\hline$[0.5,0.315]$ & 1,66 & 1,70 & 1,74 & 1,69 & 1,69 \\
\hline$[0.315,0.2]$ & 1,67 & 1,67 & 1,67 & 1,67 & 1,67 \\
\hline$[0.2,0.160]$ & 1,67 & 1,67 & 1,64 & 1,65 & 1,67 \\
\hline$[0.160,0.125]$ & 1,65 & 1,65 & 1,63 & 1,65 & 1,64 \\
\hline S1 & 1,76 & 1,73 & 1,75 & 1,74 & 1,74 \\
\hline S2 & 1,68 & 1,69 & 1,69 & 1,66 & 1,67 \\
\hline S3 & 1,72 & 1,70 & 1,71 & 1,71 & 1,71 \\
\hline S4 & 1,80 & 1,75 & 1,80 & 1,75 & 1,76 \\
\hline S5 & 1,76 & 1,75 & 1,85 & 1,79 & 1,75 \\
\hline S6 & 1,75 & 1,76 & 1,77 & 1,76 & 1,76 \\
\hline S7 & 1,67 & 1,60 & 1,67 & 1,61 & 1,63 \\
\hline S8 & 1,74 & 1,72 & 1,75 & 1,72 & 1,75 \\
\hline S9 & 1,76 & 1,76 & 1,77 & 1,76 & 1,75 \\
\hline S10 & 1,86 & 1,86 & 1,84 & 1,84 & 1,84 \\
\hline & & & & & \\
\hline
\end{tabular}

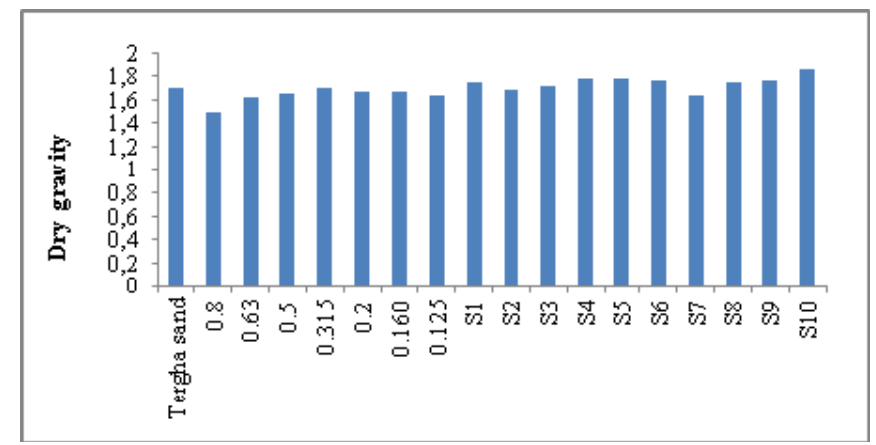

Fig. 7. Dry gravity of samples

\section{E. Results}

\section{1) Curves of shearing}

For each sample, three curves are drawn up. Figure 8 shows an example of the curves of shearing results. Table III gathers the values of the friction angle, for all samples.

2) Variation of peak friction angle $\varphi^{p}$ and critical state friction angle $\varphi^{c s}$ according to the smallest diameter of particle size range $\left(d_{i}\right)$

According to Figure 9, the points (smaller diameter of a grain size range $d_{i}$, peak friction angle $\varphi^{p}$ and critical state friction angle $\varphi^{c s}$ ), respectively, are gathered around the linear regression lines:

$$
\begin{aligned}
& \phi_{i}^{p}=34+10 d_{i} \\
& \phi_{i}^{c s}=29+3 d_{i}
\end{aligned}
$$

where:

$d_{i}[\mathrm{~mm}]$ : smallest diameter of particle size range $\left[d_{i+1}, d_{i}\right]$.

$\phi_{i}^{p}$ and $\phi_{i}^{c s}\left[^{\circ}\right]$ : represent the peak friction angle and critical state friction angle, respectively, for the particle size range $\left[d_{i+1}, d_{i}\right]$.

The results show a direct relation between particles size and peak friction angle. It is noted that there is an increase in peak friction angle with the increase of particles size. So if we know the size of particles of marine sand we can deduce directly the value of peak friction angle. On the other hand the line of variation of internal friction angle, according to $d_{i}$ is almost horizontal, which shows that there is no influence of the particles size on the internal friction angle.

TABLE III. FRICTIONS ANGLE OF SAMPLES AT PEAK AND CRITICAL STATE

\begin{tabular}{|c|c|c|}
\hline Sample & $\varphi^{\boldsymbol{P}}$ & $\varphi^{\text {CS }}$ \\
\hline Tergha Sand & 36,5 & 28,5 \\
\hline$[1 ; 0,8] \mathrm{mm}$ & 40,7 & 30,8 \\
\hline$[0,8 ; 0,63] \mathrm{mm}$ & 41,1 & 29,6 \\
\hline$[0,63 ; 0,5] \mathrm{mm}$ & 40,9 & 31,4 \\
\hline$[0,5 ; 0,315] \mathrm{mm}$ & 38,5 & 29,9 \\
\hline$[0,315 ; 0,2] \mathrm{mm}$ & 34,7 & 27,8 \\
\hline$[0,2 ; 0,160] \mathrm{mm}$ & 35,4 & 27,7 \\
\hline$[0,160 ; 0,125] \mathrm{mm}$ & 35,1 & 30,6 \\
\hline $\mathrm{S} 1$ & 38,1 & 29,1 \\
\hline $\mathrm{S} 2$ & 36,6 & 28,9 \\
\hline $\mathrm{S} 3$ & 36,7 & 28,8 \\
\hline $\mathrm{S} 4$ & 40,7 & 30,0 \\
\hline $\mathrm{S} 5$ & 38,4 & 31,5 \\
\hline $\mathrm{S} 6$ & 42,2 & 28,5 \\
\hline $\mathrm{S} 7$ & 37,5 & 31,2 \\
\hline S & 39,6 & 29,0 \\
\hline S9 & 36,1 & 26,8 \\
\hline S10 & 38,9 & 32,3 \\
\hline
\end{tabular}




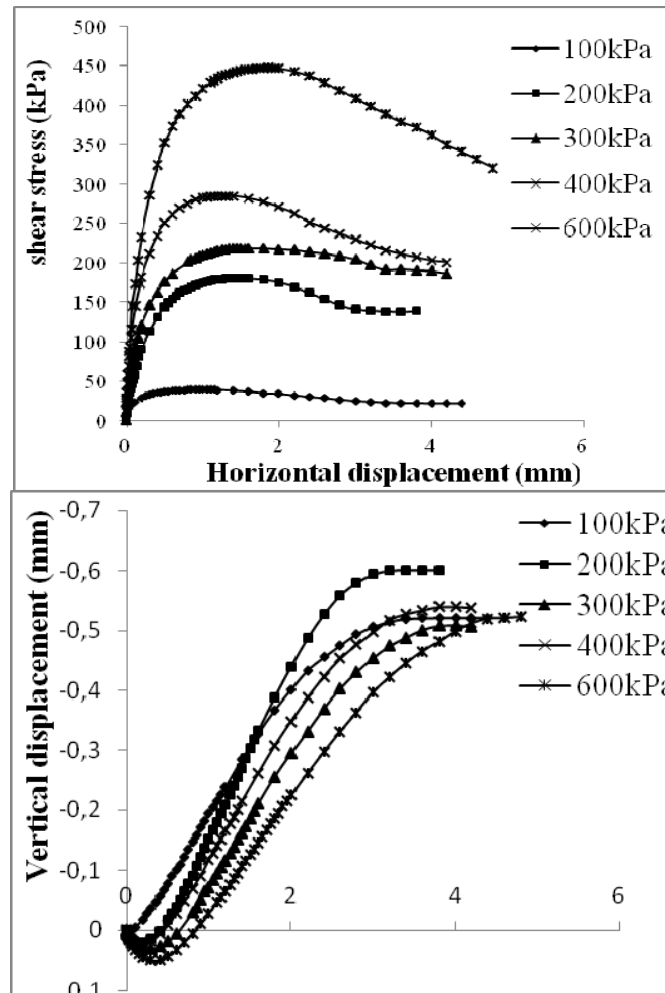

0,1

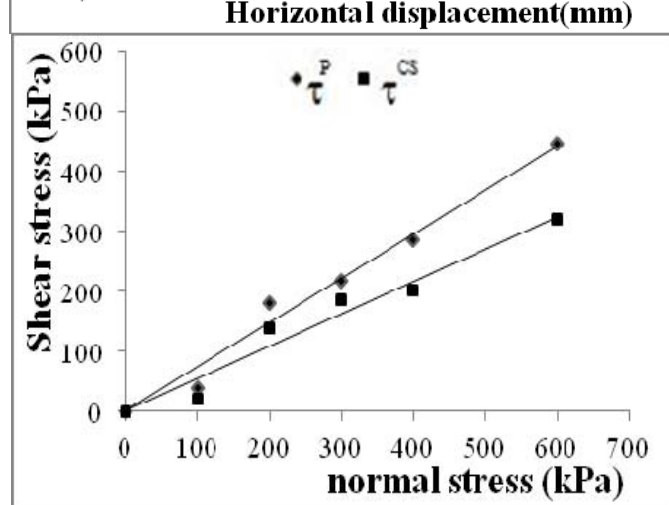

Fig. 8. Results of direct shear test on Tergha sand.

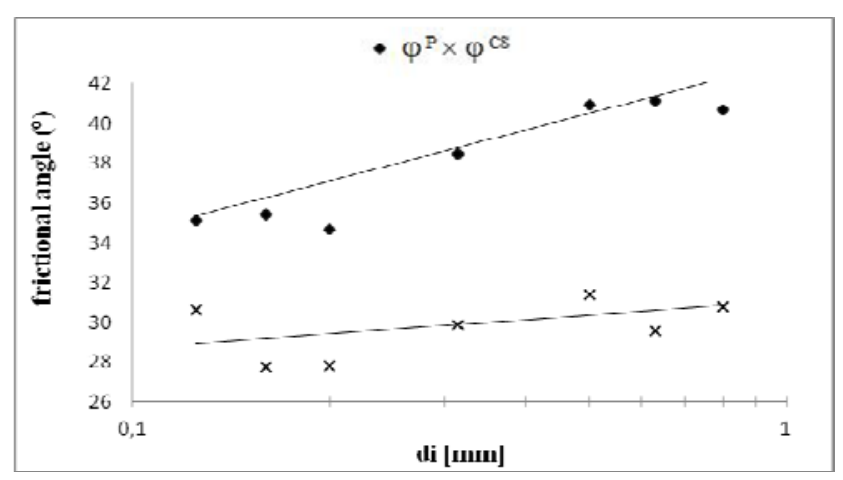

Fig. 9. Variation of $\phi_{i}^{p}$ and $\phi_{i}^{c s}$ according to $d_{i}$.
3) Contribution of particle size ranges of a sand to its peak friction angle

The use of (1), allows the determination of peak friction angle for each particle size range constituting the studied sand but not the global friction angle of sand. So we will try to determine the global peak friction angle of various sands from peak friction angles of particle size ranges constituting the same sands. For this we will study Tergha sand and the ten reconstituted samples.

Results show that the peak friction angle of each sample corresponds to the sum of the contribution of the various particles size ranges. The contribution of each class being equal to its peak friction angle balanced by its percentage in the grain-size distribution of the sample:

$$
\phi^{p}=\sum_{i} p_{i} \phi_{i}^{p}
$$

where:

$\varphi^{p}\left[^{\circ}\right]$ corresponds to the peak friction angle of sand.

$P_{i}$ : percentage of particle size range $\left[d_{i+1}, d_{i}\right]$ in the composition of sand

Figure 10 presents the comparison between peak friction angles measured in the laboratory and those calculated from (3). The use of this relation provided a calculation of the friction angle nearly identical to the values found experimentally.

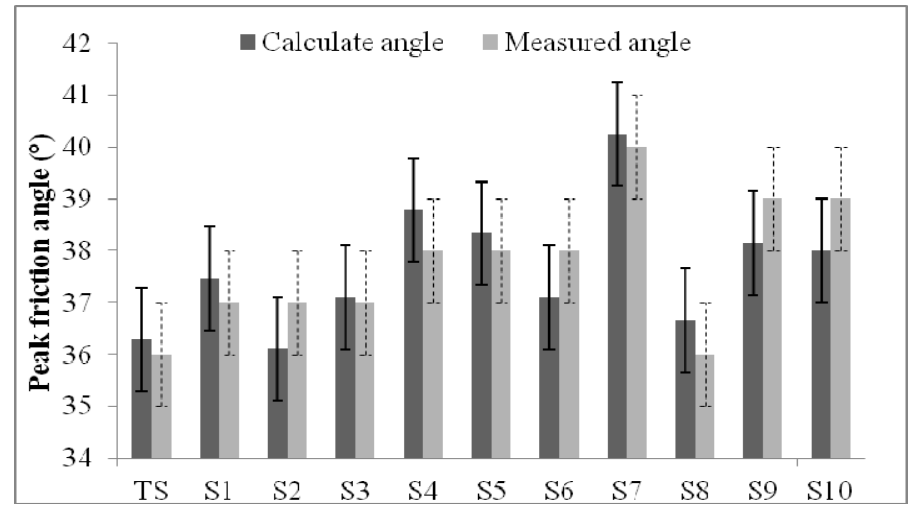

Fig. 10. Comparison between measured peak friction angle in laboratory and those calculated using (3).

Statistical analysis of the obtained results shows that a good correlation exists:

- The difference between the theoretical and experimental friction angle or absolute error is approximately, $1^{\circ}$ for six samples out of eleven, $0.3^{\circ}$ for three samples, $0.5^{\circ}$ for a sample, and $0.1^{\circ}$ for the last sample, which corresponds to an relative error of almost 2,5\%;

- Coefficient of correlation is equal to 0.862 .

- Absolute errors of friction angles, for calculated and measured values, are estimated at maximum $\pm 1^{\circ}$. 
4) Variation of peak friction angle with the smallest diameter of particls size range

If we incorporate (1) in (3), we obtain:

$$
\phi^{p}=34+10 \sum_{i} p_{i} d_{i}
$$

where:

$$
\begin{aligned}
& \varphi^{p} \text { in }\left[^{\circ}\right] . \\
& d_{i} \text { in }[\mathrm{mm}] . \\
& p \text { in [\%]. }
\end{aligned}
$$

Figure 11 shows the comparison between measured friction angle in laboratory and those calculated using (4). The correlation coefficient is 0.755 . This last equation enables us to determine the peak friction angle of sand directly from particle size $\left(d_{i}\right)$. Thus, a simple grain size analysis of sand enables us to deduce his peak friction angle.

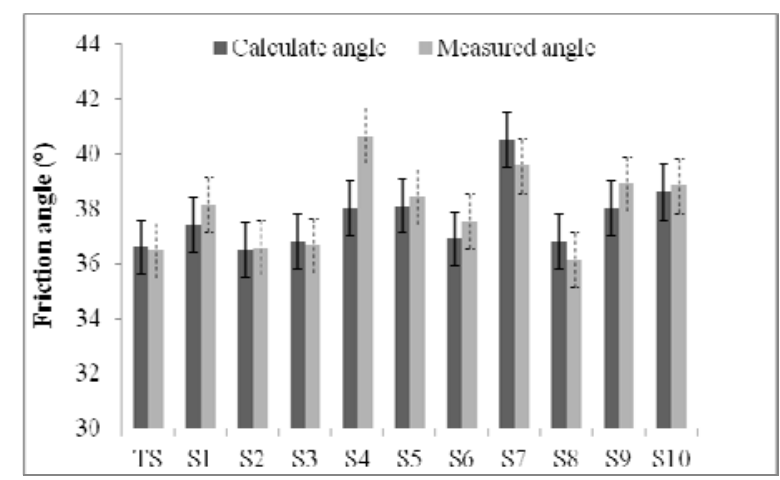

Fig. 11. Comparison between measured peak friction angle in laboratory and those calculated from (4).

\section{CONCLUSION}

At the last of this study one arrives at the following conclusions:

- Peak friction angle increases when the size of particles increases

- Grains size does not have a significant influence on internal friction angle

- Results show a relation between the grain size and the peak friction angle

- The peak fiction angle can be deduced by the sum of elementary peak friction angles, of particles size ranges constituting the sand, balanced by their percentages in grain-size distribution

- The use of (3) allowed the calculation of the friction angle which was nearly identical to the values found experimentally, the coefficient of correlation is 0.862 .

- $\quad$ By using (4) we can calculate the peak friction angle from the sum of each smallest diameter of particle size ranges balanced by its percentage in the granular composition.

- A simple grain size analysis of sand enables us to deduce his peak friction angle.

\section{REFERENCES}

[1] R. D. Holtz, W. D. Kovacs, T. C. Sheahan, An Introduction to Geotechnical Engineering, Prentice Hall, 2010

[2] J. K. Mitchell, K. Soga, Fundamentals of Soil Behavior, John Wiley \& Sons, 2005

[3] K. Terzaghi, R. B. Peck, G. Mesri, Soil Mechanics In Engineering Practice, Wiley-Interscience, 1996.

[4] P. W. Rowe, "The stress dilatancy relations for static equilibrium of an assembly of particles in contact”, Proceedings Royal Society, London, Series A, Vol. 269, pp. 500-527, 1962

[5] R. W. Yong, B. P. Warkentin, "Soil properties and behavior”, Elsevier Scientific, 1975

[6] J. C. Santamarina, G. C. Cho, "Determination of Critical State Parameters in Sandy Soils-Simple Procedure”, Geotechnical Testing Journal, Vol. 24, No 2, pp. 185-192, 2001

[7] K. Been, M. G. Jefferies, J. Hachey, "The critical state of sands", Geoteschnique, Vol. 41, No. 3, pp. 365-381, 1991

[8] E. Frossard, "Effect of sand grain shape on interparticle friction; indirect measurements by Rowe's stress dilatancy theory”, Geotechnics, Vol. 29, No 3, pp 341-350, 1979

[9] G. Viggiani, M. Kuntz, J. Desrues, “An Experimental investigation of the relationships between grain size distribution and shear banding in sand”, Continuous and Discontinuous Modeling of Cohesive Frictional Materials, Lecture Notes in Physics, Vol. 568, pp. 111-127, 2001

[10] W. B. Whalley, "Discussion on 'Effect of sand grain shape on interparticle friction’”, Geotechnics, Vol. 29, No. 3, pp 341-350, 1979

[11] N. Salimi, V. Yazdanjou, A Hamidi, "Shape and size effects of gravel grains on the shear behavior of sandy soils”, Proceedings of the 10th International Symposium on Landslides and Engineered Slopes, pp. 469474, 2008

[12] A. W. Bishop, "A large shear box for testing sands and gravels", Proceedings of the 2nd International Conference of Soil Mechanics and Foundation Engineering, Vol. 1, pp. 207-211, 1948

[13] W. M. Kirkpatrick, ” Effect of grain size and grading on shear behavior of granular materials", Proceedings of the Sixth International Conference of Soil Mechanics and Foundation Engineering, Vol. 1, pp. 273-277, 1965

[14] R. M. Koerner, "Effect of particle characteristics on soil strength", Journal of Soil Mechanics \& Foundations Division, Vol. 96, No. SM4, pp. 1221-1234, 1970

[15] J. S. Zelasko, R. J. Krizek, T. B. Edil, "Shear behavior of sand as a function of grain characteristics”, Istanbul Conference on Soil Mechanics and Foundation Engineering, Vol. 1, pp. 55-64, 1975

[16] A. W. Bishop, "Discussion to 'Messurement of the shear strength of soils' by Skempton and Bishop”, Geotechnique, Vol. 2, No. 1, pp. 113116, 1950

[17] R. M. Koerner, "Behavior of single mineral soils in triaxial shear", Journal of the Soil Mechanics and Foundations Division, Vol. 96, No. 4, pp. 1373-1390, 1970

[18] T. Kokusho, T. Hara, R. Hiraoka, "Undrained shear strength of granular soils with different particle gradations”, Journal of Geotechnical and Geoenvironmental Engineering, Vol. 130, No. 6, pp. 621-629, 2004

[19] A. Simoni, G. T. Houlsby, "The direct shear strength and dilatancy of sand-gravel mixtures”, Geotechnical \& Geological Engineering, Vol. 24, No. 3, pp. 523-549, 2006

[20] A. Hamidi, V. Yazdanjou, N. Salimi, "Shear strength characteristics of sand-gravel mixtures", International Journal of Geotechnical Engineering, Vol. 3, No. 1, pp. 29-38, 2009 